\title{
Assessment of Library Instruction for Freshmen Engineering Students
}

\section{Mr. Jeff McAdams, University of North Carolina, Charlotte}

Jeff McAdams is the Science and Engineering Librarian at The University of North Carolina at Charlotte where he works with the College of Engineering and the Mathematics and Physics departments.

\section{Dr. Rebecca Croxton, University of North Carolina, Charlotte}

Rebecca Croxton is the Head of Assessment at J. Murrey Atkins Library at the University of North Carolina at Charlotte. She completed both a $\mathrm{PhD}$ in Educational Studies and a MLIS degree from UNC Greensboro. Before completing her $\mathrm{PhD}$, she worked as a reference librarian at Johnson \& Wales University-Charlotte and Central Piedmont Community College. A large focus of her day-to-day work and research interests lies in the fields of data informed decision making, information seeking behavior, and student library engagement and motivation. 
An Assessment of the Impact of Library Instructional Strategies on

Engineering Students' Information Literacy

\author{
Jeffrey McAdams, MLS (Co-Principal Investigator) \\ Assistant Professor and Engineering Librarian, J. Murrey Atkins Library \\ Rebecca Croxton, MLIS, PhD (Co-Principal Investigator) \\ Associate Professor and Head of Assessment, J. Murrey Atkins Library
}

The authors are grateful for the collaborative support of UNC Charlotte's William States Lee College of Engineering Office of Student Development and Success instructors: Don Blackmon, Chris McDaniel, Gwen Gill, Meg Harkins, Dan Latta, Kevin Lindsay, Bill Lindsey, and Sherman Mumford.

This work was supported by funds provided by the Scholarship of Teaching and Learning Program at the University of North Carolina at Charlotte. 


\begin{abstract}
This study seeks to assess the impact of the current information literacy instruction program offered by the engineering librarian on freshmen engineering students' abilities to critically evaluate and select credible and meaningful resources in their research and writing. Trends in library literature suggest that students often skip library resources in favor of more familiar search strategies used in their daily lives. However, there is significant, positive correlational evidence which suggests that using the library is closely associated with students' academic performance and university retention. In order to determine if the local library intervention has an effect, this study includes multiple data sources that are used to examine students' information literacy skills, comparing findings between those who have engaged with the library's information literacy instruction program and those who have not. Currently, students voluntarily attend a library workshop and/or a peer-mentoring program that utilizes an online library assignment, each of which is focused on an end-of-semester research paper. This study uses data from four groups of students and analyzes the degree of success for the library interventions. The methods and data are presented for analysis. The findings from this study will be used to make improvements to the local information literacy curricula and to develop a replicable model for information literacy instruction that will promote student success and retention through graduation.
\end{abstract}


In universities throughout the United States, student retention is a critical issue. The U.S. Department of Education, National Center for Education Statistics (2017) recently reported that $59 \%$ of first-time full-time students who began seeking a bachelor's degree at a 4-year institution in fall 2007 completed the degree at that institution by 2013. The academic library is equipped to play a critical role in engaging students in the university systems, thus having the potential to positively affect student retention. However, current trends suggest undergraduate students are turning away from their academic libraries in favor of more attractive alternatives for their information seeking (Colón-Aguirre \& Fleming-May, 2012; Denison \& Montgomery, 2012). While academic libraries have long been heralded as the heart of the university (Leupp, 1924), today's undergraduate learners are opting for quick, easy, and more convenient alternatives to meet their information needs that do not include the library (Colón-Aguirre \& Fleming-May, 2012; Denison \& Montgomery, 2012; Mizrachi, 2010).

This turning away from the academic library elicits concern as significant, positive correlational evidence suggests library utilization is closely related to students' academic performance (Goodall \& Pattern, 2011; Wong \& Webb, 2011) and university retention (Haddow, 2013; Mezick, 2015; Soria, Fransen, \& Nackerud, 2013, 2014). Despite efforts to improve information literacy and increase students' willingness to use the library, the efficacy of this work lies in question (Coulter, Clark, \& Scamman, 2007; Detlor, Booker, Serenko, \& Julien, 2012). Rempel and Cossarini (2013) noted that many students rely on Google for finding materials to support their research, despite the fact that these students have received library instruction that highlighted the value of using library resources. In a separate study, Colón-Aguirre \& Fleming-May (2012) found that undergraduates do not find library instruction 
sessions relevant to their practical information needs and many students do not come away from library information sessions feeling fully prepared or willing to move beyond Google and into the library for conducting their information searches. In response to these trends, research and instruction librarians at academic libraries across the nation continue to develop a variety of information literacy curricula that they believe will effectively teach students to become informationally literate, willing and able to competently and critically evaluate, select, and ethically utilize the most appropriate sources available for their research and writing. It is the goal of this study to assess the effectiveness of these efforts at one large-sized public university in the southeastern United States, specifically for engineering students. The findings of this study will not only help to improve the information literacy instructional curricula at higher education institutions, but will also provide an innovative and tested approach to evaluating the effectiveness of instruction offered by the library. Findings from this study will be used to develop a transferable model for information literacy instruction and assessment.

\section{Literature Review}

Assessing student learning from an information literacy session has always been a multi-faceted problem, depending on what the outcomes are and how engaged the students are with those outcomes, whether during the session or in class through discussion or a project they turn in. Other librarians using bibliographies and evaluation of citations have shown different methods over time. Measuring the bibliographies have limitations, but they also show the students" "ability to select and retrieve relevant sources, and as well as their desire to do so" (Middleton, 2005). Ursin, Lindsay, and Johnson (2004) did a citation analysis of freshman seminar student bibliographies. The librarians compared the sources to ones listed in library 
research guides. They also created an evaluation rubric for websites so they could determine the quality of that resource relative to the assignment. However, these methods did not address why the student chose the particular source for their paper. One study used student bibliographies and their papers to evaluate their performance on 8 separate outcomes, including citation quality, source quality, and source analysis (Luetkenhaus, Borrelli, \& Johnson, 2015). This provided some guidance in our objectives with this study. Another study compared citations from students who participated in an information literacy class and those who did not (Cooke \& Rosenthal, n.d.). They did a quantitative analysis only of the number and diversity (format) of citations between the two groups.

One aspect of evaluating students' performance is to understand what they think of it and to find out why they chose certain resources over others to include in their work. Mark (2011) completed a focus group study that asked students about the format of information they cited as well as how they evaluated it. This study found that engaging with students to discover their understanding of credibility and type of resource (format) was very important to help the library instructor identify misconceptions and the students' desire to choose the best material even if confused about what that might be according to their instructors.

From these previous studies, the researchers in the current study have used variations of these techniques with regard to the contextual assignment in one class for engineering undergraduates. The research questions being asked are thus: How effective are the current information literacy instructional strategies and tools in teaching engineering students how to critically evaluate and select credible and meaningful resources in their research and writing? Is 
there a difference in the types and quality of resources used by students between those who participated in elective information literacy instruction and those who did not?

\section{Methods}

To assess the effectiveness of the current information literacy strategies in teaching students entry-level engineering students how to critically evaluate and select credible and meaningful resources in their writing, this study used a sequential mixed methods design conducted in two phases at a large-sized public university in the southeastern United States with a student population of approximately 29,000 . The research team is comprised of two librarian/faculty researchers employed by the university's main library in cooperation with instructional faculty and students of engineering college at the university. One researcher is the Engineering Librarian for the university, the other is the library's Head of Assessment.

\section{Study Design}

Mixed research and analysis was selected for this study, as quantitative and qualitative data, when used alone, were insufficient to answer the study's research questions (Creswell \& Plano Clark, 2011). A mixed design is further justified as allows for the triangulation of findings across multiple data sources (Green, Caracelli, \& Graham, 1989). The study is being conducted in two phases. Findings from Phase I of the study, which occurred during the Fall 2017 semester, were used to inform the design of Phase II in which participant recruitment strategies and evaluation rubrics were modified as needed and a new round of data collected and analyzed to more fully address the study's research questions. This manuscript presents the findings from Phase I along with recommendations for modification to the study design for Phase II. A second 
iteration of the paper will be written to include results from Phase II, which will take place during the Spring 2018 semester.

\section{Participants}

In Phase I of the study, all students who were enrolled in the university’s Introduction to Engineering course (ENGR 1201 or ETGR 1201) during the Fall 2017 semester were invited to participate. In all, there were 576 students enrolled in these courses and 10 individuals elected to participate with a $1.7 \%$ response rate, much lower than desired and anticipated. Because the number of participants was lower than desired in Phase I, the recruitment plan for Spring 2018 was revised to include participation incentives - $\$ 5.00$ restaurant gift cards to a nearby fast food restaurant offered to all individuals who agree to participate as well as a chance to win one of six \$25 gift cards to the campus bookstore.

In Phase I, the 10 study participants were divided into four groups based upon their engagement in supplemental information literacy instructional sessions or activities as outlined in Table 1. Each semester, the engineering librarian teaches voluntary information literacy workshops and provides a supplemental information literacy module through Canvas, the university’s Learning Management System; both interventions are designed specifically for ENGR/ETGR 1201 students. Students who attend the in-person information literacy workshop are awarded extra credit points by their course professor for their participation. No incentives are provided for use of the online information literacy module. Participation lists from the information literacy activities and ENGR/ETGR 1201 enrollment rosters were used to create four comparison groups (Table 1): Group 1 is comprised of students who participated in both the information literacy workshop as well as the online information literacy module, Group 2 are 
students who attended only the information literacy workshop, Group 3 participants used only the online module, and Group 4 neither attended the information literacy workshop or engaged with the online information literacy module.

Table 1: Research Study Groups

\begin{tabular}{|c|c|c|c|c|}
\hline Group & $\begin{array}{c}\text { Attended } \\
\text { Information } \\
\text { Literacy Workshop }\end{array}$ & $\begin{array}{c}\text { Completed Online } \\
\text { Information } \\
\text { Literacy Module }\end{array}$ & $\begin{array}{c}\text { Fall 2017 } \\
\text { Participants } \\
(\mathrm{n}=10)\end{array}$ & $\begin{array}{c}\text { Spring 2018 } \\
\text { Participants } \\
(\mathrm{n}=\mathrm{TBD})\end{array}$ \\
\hline 1 & Yes & Yes & 2 & TBD \\
\hline 2 & Yes & No & 2 & TBD \\
\hline 3 & No & Yes & 4 & TBD \\
\hline 4 & No & No & 2 & TBD \\
\hline & & Total Participants & 10 & TBD \\
\hline
\end{tabular}

\section{Data Collection Instruments}

Data collected for this study are primarily qualitative, with some transformation of qualitative data into a quantitative format to allow for a rubric score calculation and evaluation. For each phase of the study, data were collected near the end of an academic semester (F17 and S18), after ENGR/ETGR 1201 students submit their "Whole Life Concept Project" papers to their instructors for grading. The Whole Life Concept Project is the major research and writing assignment for the course. Data collection instruments used/planned for each phase of the study are outlined below as either a Final Course Activity Instrument or a Supplemental Activity Engagement Instrument.

Final course activities instruments. 
Final course activities instruments are those designed to collect artifacts of learning for evaluation of a student's ability to critically evaluate and select credible and meaningful resources in their research and writing.

- Source Justification Activity - After submission of their end-of-semester Whole Life Concept Projects, all ENGR/ETGR 1201 were emailed a Google Form by the engineering librarian (study co-investigator) which includes an electronic Informed Consent Document and invitation to participate. If they consented to participate, students were asked to (1) choose a source that they used in their Whole Life Concept Project and think critically about it, (2) paste the citation of the source into the Google Form, and (3) in a short paragraph, describe the characteristics of the source and explain why they chose it for their college project. (See Appendix A.)

- Whole Life Concept Project Paper - Citation Analysis - For all study participants, ENGR/ETGR 1201 professors shared electronic copies of their Whole Life Concept Project papers with the researchers for citation analysis. A copy of the Assignment Directions are included in Appendix B.

- Focus Groups - In the initial study design, individuals who met specific parameters (e.g., attended/ completed at least one information literacy activity OR did not participate in any information literacy activities) would be randomly selected and invited to participate in a focus group to discuss their research techniques and challenges. Focus groups were originally planned to occur in both Phase I and Phase II of the study. However, due to limited participation in Phase I, focus groups will only occur in Phase II. (See Appendix C.) 


\section{Supplemental course activities engagement instruments.}

The supplemental course activities engagement instruments are those designed to collect student artifacts of learning to allow the researchers to determine each participant's level of engagement in the supplemental information literacy activities.

- Workshop Submission Form - Participants who attended a voluntary information literacy workshop were asked to complete three tasks which were submitted to the librarian via Google Form. First, participants were asked to find a website they might use for their research paper, provide a link, and identify the publisher of the site. Second, participants were to evaluate the website they identified. Finally, participants were prompted to create a citation of a different source that they might consider using in their papers. (See Appendix D.)

- Online Module Engagement - The engineering librarian also created a voluntary online module which was embedded into Canvas, the university's learning management system. Students could work through this module to receive guidance on narrowing their research topics and identifying key words to use in their searches. Student artifacts of engagement with this module included a research topic tree, a key word tree, and a written reflection. (See Appendix E.)

\section{Assessment Instruments}

Two assessment instruments were developed by the researches based upon the unique needs of the study. The Final Course Activities Evaluation Rubric was developed to evaluate and provide a total score relating to whether, or how well, a student could critically evaluate and select credible and meaningful resources in their research and writing. A second rubric, the 
Supplemental Course Activities Engagement Rubric,was developed in order to better understand how engaged each participant was in the supplemental information literacy activities made available to them by the engineering librarian.

\section{Final course activities evaluation rubric.}

The Final Course Activities Evaluation Rubric was developed to evaluate three elements related to the students' final course activities: (1) source justification activity, (2) final paper citation format, and (3) final source value (Appendix F). A modified negotiated coding approach was used to assign values for each of the three items. Garrison, Cleveland-Innes, Koole, and Kappelman (2006) described the negotiated coding approach as one in which the researchers individually code each item and then actively discuss their codes in attempt to arrive at a final version in which the coded items are brought into alignment. In the modified negotiated coding process used for this study, the two researchers met, critiqued each element, and together decided upon a score.

For the Source Justification Activity, participants were asked to select a source they used in their final paper, describe the characteristics of the source, and explain why they chose it for their college project. Each submission was critiqued and given a score ranging from 0-3 in which a score of 0 indicated a Pre-Beginning Phase, 1 was Beginning, 2 was Developing, and 3 indicated an Exemplary ability to critically evaluate a source and justify the inclusion of it in a the final paper. These ratings describe the students' fluency of skill or effort in any particular activity.

For the final paper submissions (Whole Life Concept Paper), the first three citations included in the paper bibliography were individually evaluated based upon adherence to the 
required Citation Style format (Chicago Manual of Style) and the Value each added to the paper. The citations were first given a citation format score ranging from 0-3. A score of 0 indicated that no citation was included, a score of 1 was given if the student made an attempt at citing a source such as including a link or only parts of a citation, a score of 2 indicated that all of the pieces of a citation were included, but there were stylistic errors, and a score of 3 was given if a citation was perfectly formatted. These three citation format scores were then averaged and scores were entered into the Final Course Activities Evaluation Rubric.

In addition to format scores, the same three citations/sources were then evaluated based upon whether the source materials provided value to the paper. Value was defined by the researchers as presenting a new idea, providing evidence to support an argument, and/or explaining a concept. If a source met this criteria, it was given a score of 1 ; a score of 0 indicated that the source did not fulfill any of these criteria. These Source Value scores were then averaged and entered into the Evaluation Rubric. Scores for all three evaluation components were then summed to provide a Final Course Activities Score, with a total of 7 points possible ( 3 for Source Justification Activity +3 for Citation Format Average +1 for Source Value Average). These scores were then compared across participants and participant groups as a way to look for trends as an indicator of effectiveness of information literacy activities.

\section{Supplemental course activities engagement rubric.}

To measure each participant's level of engagement with the supplemental course activities (attendance at the information literacy workshop and engagement with the online module), a second rubric was created by the researchers that included four elements for assessment: (1) workshop - publisher identification, (2) workshop - source evaluation, (3) 
workshop - citation format, and (4) online module engagement (Appendix G). For the workshop - publisher identification element, if a student correctly identified the correct publisher, they received a score of 1 ; if they did not, they received a 0 . Similar to the Final Course Activities Evaluation Rubric, each workshop - source evaluation submission was critiqued and given a score of 0-3 in which a score of 0 indicated a Pre-Beginning Phase, 1 was Beginning, 2 was Developing, and 3 indicated an Exemplary ability to critically evaluate a source and justify its inclusion in a paper. Likewise, the workshop - citation was also evaluated using the same criteria used in the Final Course Activities Evaluation Rubric, using a rating system of 0-3. A score of 0 indicated that no citation was included, a score of 1 was given if the student made an attempt at citing a source such as including a link or only parts of a citation, a score of 2 indicated that all of the pieces of a citation were included, but there were stylistic errors, and a score of 3 was given if a citation was perfectly formatted. Finally, engagement in the online module activities was evaluated via a simple counting of the number of elements (research topic tree, a key word tree, written reflection) submitted by the student, ranging from 0-3. The scores for each element were tallied to provide a Supplemental Activities Engagement Score with a total of 10 points possible ( 1 for Workshop Publisher Identification +3 for Workshop Source Evaluation +3 Workshop Citation Format +3 Online Module Elements).

\section{Results}

Group 1 (participated in the library workshop and the online module) was comprised of two students. Their mean engagement score was 5.50 combined for both activities. One of the students had a high engagement score of 7 while the other student had a low engagement of 4 . The mean final evaluation score was 2.65. It is interesting to note that the more engaged student 
had a higher final evaluation score, although two data points cannot point to any conclusions. Group 2 (participated in the library workshop only) was comprised of two students, as well. Their mean engagement score was 4.50 for the library workshop. Their engagement scores were less because they participated in one fewer activities. Their mean final evaluation score was 3.67. Group 3 (participated in the online module only) was comprised of four students. Their mean engagement score was 1.50. Their mean final evaluation score was 3.42. Group 4 (did not participate in any library activities) was comprised of two students. Their mean engagement score was 0 . Their mean final evaluation was 4.92 . This group had the highest evaluation score of all groups, which was interesting since they had no contact with the library.

Group 4 had the highest final evaluation score, followed by Group 2 (3.67), then by Group 3 (3.42), and finally by Group 1 (2.65) (Table 2 and Figure 1). With the exception of Group 4, who had no engagement score, the other individuals had different engagement scores within their groups. No one student behaved like the other. The researchers could not elicit many patterns of behavior because of so few participants in each group.

Table 2: Group x Engagement x Final Evaluation

\begin{tabular}{|c|c|c|}
\hline Group \& Participant & $\begin{array}{l}\text { Engagement Score } \\
\text { (10 point maximum) }\end{array}$ & $\begin{array}{l}\text { Final Evaluation Score } \\
\text { (7 point maximum) }\end{array}$ \\
\hline \multicolumn{3}{|c|}{ Group 1 (Workshop + Online Module) } \\
\hline Participant 1 & 4.00 & 2.00 \\
\hline Participant 2 & 7.00 & 3.33 \\
\hline Group 1 Mean & 5.50 & 2.65 \\
\hline \multicolumn{3}{|c|}{ Group 2 (Workshop Only) } \\
\hline Participant 8 & 4.00 & 4.67 \\
\hline Participant 10 & 5.00 & 2.67 \\
\hline
\end{tabular}




\begin{tabular}{|c|c|c|}
\hline Group 2 Mean & 4.50 & 3.67 \\
\hline \multicolumn{3}{|c|}{ Group 3 (Online Module Only) } \\
\hline Participant 4 & 2.00 & 4.50 \\
\hline Participant 5 & 1.00 & 2.50 \\
\hline Participant 6 & 3.00 & 3.00 \\
\hline Participant 9 & 0.00 & 3.67 \\
\hline Group 3 Mean & 1.50 & 3.42 \\
\hline \multicolumn{3}{|c|}{ Group 4 (No Supplemental Activities) } \\
\hline Participant 3 & 0.00 & 5.50 \\
\hline Participant 7 & 0.00 & 4.33 \\
\hline Group 4 Mean & $\mathbf{0}$ & 4.92 \\
\hline
\end{tabular}

Figure 1: Group x Engagment x Evaluation

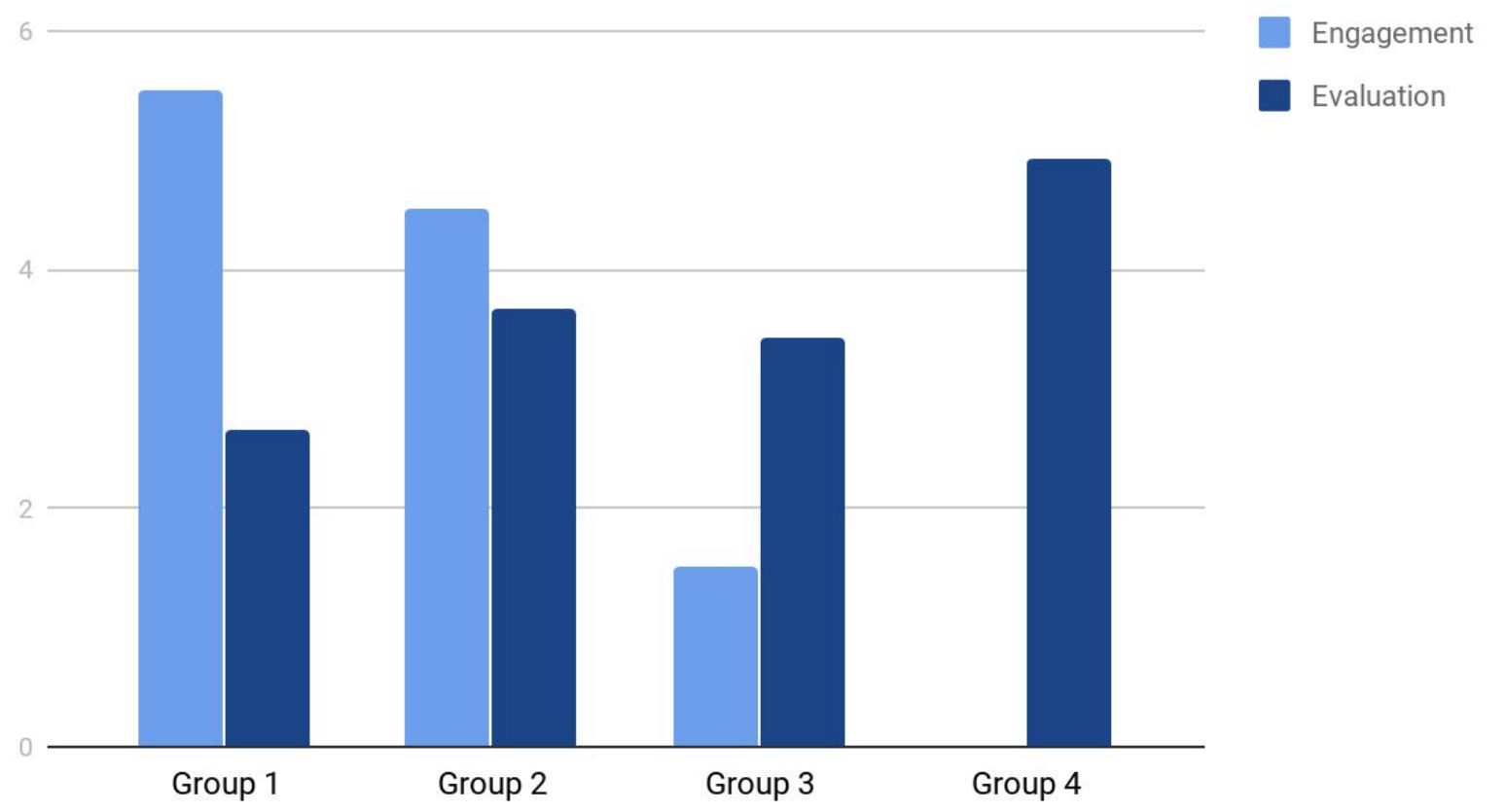




\section{Discussion}

The findings of this preliminary study are limited and inconclusive due to the small number of students in our survey. Only 10 out of 576 students enrolled in these courses elected to participate. The 10 students who consented to participate did coincidentally divide almost evenly into 4 groups of 2 or more. However, 2 students in each group is unrepresentative statistically. In any of the groups, one of the students could be an outlier that can significantly skew the data. The researchers were unable to hold a focus group study as part of this preliminary analysis, but plan to do so in the future. Some information to be collected in the focus groups will include student motivation in participating or not with library activities, their confidence levels for research skills, and what, if any, concepts or skills they found helpful in or out of class or library activities to incorporate in their assignment. If any findings could be made from this limited study, they would read that the less engagement with library activity, then the higher the evaluation the student made. This would make for a very interesting finding, prompting the researchers to question why. As this study moves to phase II, the focus groups will probe into student reflection on their own research behavior, which might shed light onto any previous experiences or engagement they may have had.

With the lack of concrete findings, the focus of this paper is to share the researchers' methodology of assessment. The library activities offered to students with this course assignment have been around for a few years. The researchers set out to assess the common theme in all of them, which is evaluation of a source material in relation to this paper. The website evaluation activity in the library workshop asks the students to think critically about the qualities of a website randomly found on a topic and how to describe them as adequate or 
inadequate for university research. The accompanying citation activity can also be boiled down to evaluation of a source. The student must recognize and understand what type of source they are looking at in order to cite it correctly in Chicago Manual of Style. This is a fundamental type of evaluation and is easy for the librarian to assess. However, the online module activities are not specifically evaluative in nature, but they are tangentially related. They require the student to think critically about their topics and keywords, which are skills that help in evaluation later. They are asked to reflect on their participation which is an evaluative act. The final survey the librarian sent to the students asks them to choose a resource from their bibliography and evaluate the successful use of it in their paper. Finally, their bibliography citations are assessed for accuracy which can tell if they were able to evaluate what type of resource they used correctly. These student evaluations were assessed by using rubrics the researchers developed in a progressive skills level (e.g. pre-beginning, beginning, developing, and exemplary). These numbers were added up and compared against each other to determine how well the students were able to critically evaluate and select credible and meaningful resources in their research and writing. The researchers were looking if any correlation could be shown in relation to the level of engagement the students had with the various library activities, but were unable to answer this question due to limited sample size.

The goals of this project were to devise an assessment methodology to implement in order to understand what, if any, impact the library activities may have on student success with their assignment in this course. In the future, as the methods are tightened, the librarian hopes to be able to tweak the library activities appropriately and reassess their impact to see if progress is being made or not. Although the researchers report no conclusive findings at this time, they feel 
that this method can work if larger numbers of students consent to interact. For the next phase, they will try with incentives of gift cards and email marketing with improved graphics. In addition, the researchers suspect there may be possible group differences based upon original admission status (e.g. new freshmen or transfer), age, and if the student has received library instruction the past. The results will be presented in another paper in the future. 


\section{References}

Colón-Aguirre, M., \& Fleming-May, R. A. (2012). "You just type in what you are looking for": Undergraduates' use of library resources vs. Wikipedia. Journal of Academic Librarianship, 38, 391-399.

Coulter, P., Clarke, S., \& Scamman, C. (2007). Course grade as a measure of effectiveness of one-shot information literacy instruction. Public Services Quarterly, 3, 147-163.

Denison, D. R., \& Montgomery, D. (2012). Annoyance or delight? College students' perspectives on looking for information. Journal of Academic Librarianship, 38, 380-390. http://dx.doi.org/10.1016/j.acalib.2012.08.007

Detlor, B., Booker, L., Serenko, A. \& Julien, H. (2012). Student perceptions of information literacy instruction: The importance of active learning. Education for Information, 29, $147-161$.

Garrison, D. R., Cleveland-Innes, M., Koole, M., \& Kappelman, J. (2006). Revisiting methodological issues in transcript analysis: Negotiated coding and reliability. Internet and Higher Education, 9, 1-8.

Goodall, D., \& Pattern, D. (2011). Academic library non/low use and undergraduate student achievement: A preliminary report of research in progress. Library Management, 32, 159-170.

Green, J. C., Caracelli, V. J., \& Graham, W. F. (1989). Toward a conceptual framework for mixed-method evaluation designs. Educational Evaluation and Policy Analysis, 11, 255-274. 
Haddow, G. (2013). Academic library use and student retention: A quantitative analysis. Library \& Information Science Research, 35, 127-136.

Leupp, H. L. (1924). The library: The heart of the university. Bulletin of the American Library Association, Papers and Proceedings of the Forty-Sixth Annual Meeting of the American Library Association, 18, 193-197.

Luetkenhaus, H., Borrelli, S., \& Johnson, C. (2015). First Year Course Programmatic Assessment: Final Essay Information Literacy Analysis. Reference \& User Services Quarterly; Chicago, 55(1), 49-60.

Mark, A. E. (2011). Format as a False Judge of Credibility: Messages from Librarians and Faculty and Student Responses. Communications in Information Literacy, 5(1), 21-37.

Mezick, E. M. (2015). Relationship of library assessment to student retention. Journal of Academic Librarianship, 41, 31-36.

Middleton, A. (2005). An attempt to quantify the quality of student bibliographies. Performance Measurement and Metrics; Bradford, 6(1), 7-18.

Mizrachi, D. (2010). Undergraduates' academic information and library behaviors: Preliminary results. Reference Services Review, 38, 571-580. doi:10.1108/00907321011090737

Rempel, D., \& Cossarini, D. M. (2013). Communicating the relevance of the library in the age of Google: Improving undergraduate research skills and information literacy through new models of library instruction. Nordic Journal of Information Literacy in Higher Education, 5, 49-53. 
Soria, K. M., Fransen, J., \& Nackerud, S. (2013). Library use and undergraduate student outcomes: New evidence for students' retention and academic success. Portal: Libraries \& The Academy, 13, 147-164.

Soria, K. M., Fransen, J., \& Nackerud, S. (2014). Stacks, serials, search engines, and students' success: First-year undergraduate students' library use, academic achievement, and retention. Journal of Academic Librarianship, 40, 84-91.

Ursin, L., Lindsay, E. B., \& Johnson, C. M. (2004). Assessing library instruction in the freshman seminar: a citation analysis study. Reference Services Review, 32(3), 284-292.

U.S. Department of Education, National Center for Education Statistics. (2017). The condition of education 2017 (NCES 2017-144). Retrieved from https://nces.ed.gov/pubsearch/pubsinfo.asp?pubid=2017144 


\section{Appendix A: Source Justification Instrument}

Screenshot of Google Form used to collect data.

\section{Source Evaluation}

Choose a source you used in your Whole Life Concept Project and think critically about it.

Paste the citation of the source here *

Long answer text

Write why you chose this particular source *

In a short paragraph, describe the characteristics of the source and explain why you used it for your college project.

Long answer text

Name (First and Last) *

Short answer text

Course Section Number *

e.g. $001,003,024$, etc. You can look at your syllabus or look in Canvas if you don't know.

Short answer text

800 Number * 


\section{Appendix B: Whole Life Concept Assignment Directions}

\section{Background}

You have completed Part 1 of the Whole Life Project by submitting a memo defining, in detail, your expectations ("passion" and "impacts") and goals for the three, five, and ten years following your college graduation. That passion and those goals and impacts involve a certain set of skills and knowledge that you must learn and develop to be successful. You must also learn to apply those skills and that knowledge in an efficient and effective manner.

\section{Purpose:}

The purpose for Part 2 of the project is for you to complete and document high quality research into the skills and knowledge you will need to achieve your short and long-term goals. Then you will need to research and document where you can obtain those specific skills and knowledge. Finally, you must be willing to make the commitment to develop those skills, knowledge, and applications.

\section{Introduction}

- Briefly address the purpose of the overall project and how this part fits into the whole project.

\section{Research of Skills, Knowledge, and Applications}

- Identify and describe (in detail) specific knowledge (course content) and skills that would be gained in technical and non-technical courses and laboratories to provide you with the fundamental academic knowledge needed to meet your three, five, and ten year goals.

- Provide three specific examples of course material you expect to use to achieve your desired goals. For example, you may choose to take a course in nuclear engineering to develop your knowledge of nuclear power plants with the goal of developing cleaner energy systems for developing nations.

- Identify and describe other specific areas of knowledge, skills, and abilities you will need to master to achieve the goals you have previously identified.

- Identify and provide details of the sources you will use to develop the specific nontechnical, non-academic knowledge, skills, and abilities you will need to achieve the impact you desire. 
Following your work to identify your passion and specific three, five, and ten year goals, and your work to identify specific skills, knowledge, and abilities needed to achieve those goals, it is time to identify the educational major options available to you that will provide the best match to your needs.

\section{Findings and Conclusions}

To successfully complete this part of the Whole Life Project you will need to use the results from your research to:

- Identify your educational major, or the major you are considering.

- Discuss why you believe that the major you identified is the best fit for you in terms of turning your passion into a career to meet the three, five and ten year goals. Include at least two example to support your choice of major.

- Provide three specific examples and explain how the non-technical, non-academic programs you have chosen will help you in achieving your goals.

- Reflect on your commitment to your engineering, engineering technology, or construction management degree. Describe, in detail, why you are - or are not - more committed now than before to your chosen major, the College of Engineering, and/or UNC Charlotte,

\section{Successful Completion of the Assignment}

You will submit this assignment to your manager and supervisor for comment and grading as proscribed in the Written Assignments Policy. The Whole Life Project - Part 2 should be developed as a formal research report limited to a Report Cover Sheet, four well written pages (maximum) and a citations page. Grading will address both your response to the assignment materials and the mechanics of the assignment.

You must submit a draft of your research report 24 hours before the assignment due date and time to receive full credit for this assignment. Your draft must be reviewed by a tutor in the UNC Charlotte Writing Resource Center (http://writing.uncc.edu/writing-resources-center), a classmate, your roommate, or a parent using MS Word Revision mode. Share a copy of this assignment description with your reviewer. Ask for feedback relative to grammar, format, content, and written communications skills. Evaluate the feedback from your reviewer and incorporate it into your final document as appropriate. The draft with comments must be submitted via Canvas as a Word document with MS Revision Mode turned on, at least 24 hours BEFORE THE PAPER DUE DATE AND TIME. 


\section{Appendix C: Focus Group Questions}

1. Did you feel the library activity helped when you worked on the Whole Life Concept project?

2. Did you have trouble finding good resources?

3. What were your research methods?

4. What was challenging about documenting sources in your paper?

5. Tell me about challenges you had when beginning your research? (topic, narrowing, etc.)

6. Tell me about challenges you had when putting it all together at the end? (organizing, citing, etc.)

7. What would be helpful for future students? 


\title{
Appendix D: Workshop Data Collection Form
}

\author{
Using Google \\ Open a new browser window and go to Google.
}

Try a search for a web page for your Whole Life Concept paper, and copy and paste the URL here.*

Who is the publisher of this site?*

This is the agency, company, or group that is responsible for the information posted.

Do you think this website is reliable enough to use as a research source for a college-level paper? Why?* Explain why you would or would not trust the author and/or publisher of this site to give good information on the topic you are researching.

\section{Library research guide}

Open the research guide in another browser window - http://guides.library.uncc.edu/ENGR_1201

Of the different tools listed on the Whole Life Concept paper tab, which one would you use to find resources relating to your passion and impact?*

Go to that source, search for an item you could use in your paper, and cite it here in Chicago Style format." Use an online guide linked on the front page of the research guide for help formatting your citation 


\section{Appendix E: Online Module Subject \& Keyword Activities}

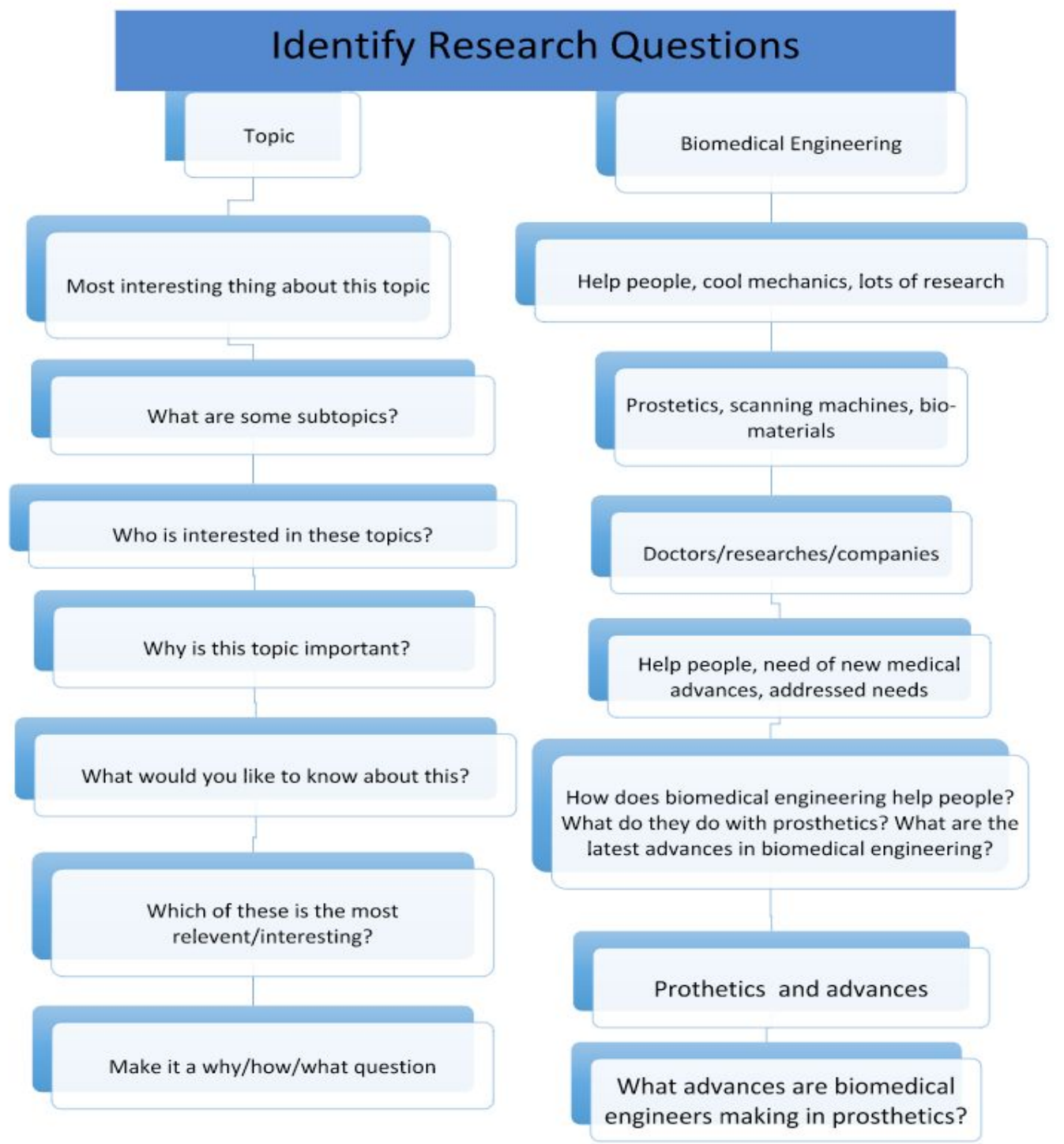




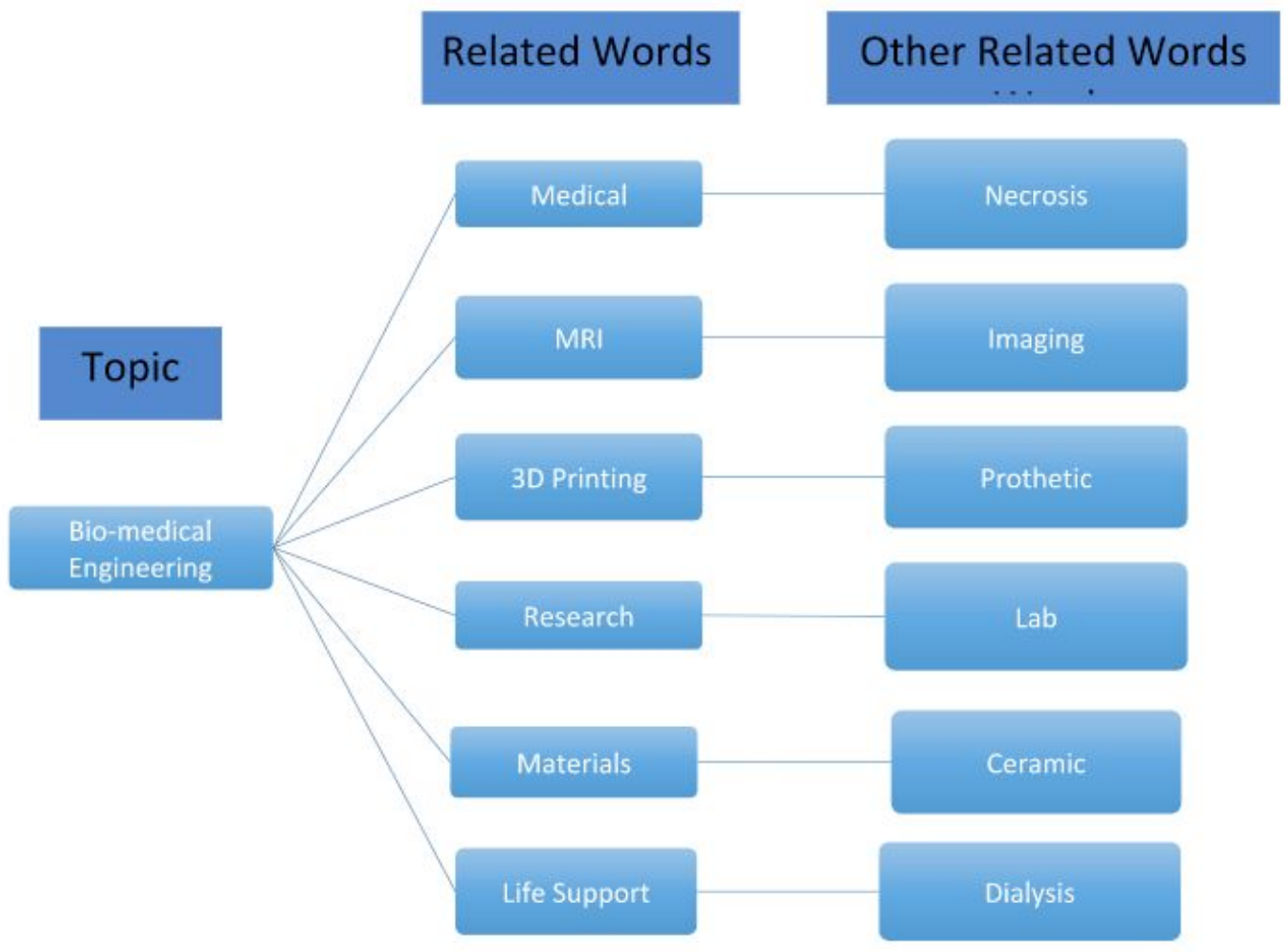




\title{
Appendix F: Evaluation Rubric
}

\author{
Participant ID:
}

Final Course Activities

\begin{tabular}{|l|l|}
\hline Survey - Source Justification Activity & Score \\
\hline 0: Pre-Beginning (Does not understand what is being asked) & \\
1: Beginning (Describes source as accurate, reliable, or relevant with no elaboration) & \\
2: Developing (Describes why a source is accurate, reliable, or relevant, but justification is & \\
not fully mature or does not evaluate source material) & \\
3: Exemplary (Describes why a source is accurate, reliable, or relevant and includes an & \\
evaluation of the source material) & \\
\hline
\end{tabular}

\section{Final Paper - Analysis of Paper Citation Format (Chicago Manual of Style) (first three citations in bibliography)}

0 : No citation included

1: Made an attempt at citing source (e.g., link only, only parts of a citation)

2: Has all the pieces required for citation, but has stylistic errors

3: Perfectly formatted citation

\begin{tabular}{|l|l|l|c|}
\hline & & & Average \\
Citation \#1 & Citation \#2 & Citation \#3 & Score \\
\hline & & & \\
\hline
\end{tabular}

Final Paper - Analysis of Citation Value (first three citations in bibliography)

0: Source does NOT present a new idea, provide evidence to support an argument, or explain a concept.

1: Source presents a new idea, provides evidence to support an argument, and/or explains a concept

\begin{tabular}{|l|l|l|c|}
\hline Citation \#1 & Citation \#2 & Citation \#3 & $\begin{array}{c}\text { Average } \\
\text { Score }\end{array}$ \\
\hline & & & \\
\hline
\end{tabular}

Final Course Activities Score

\begin{tabular}{|c|c|c|c|c|c|}
\hline $\begin{array}{c}\text { Survey - Source Justification } \\
\text { Activity (0-3) }\end{array}$ & $\begin{array}{c}\text { Final Paper - Analysis of } \\
\text { Paper Citation Format (0-3) }\end{array}$ & $\begin{array}{c}\text { Final Paper - Analysis of } \\
\text { Citation Value (0-1) }\end{array}$ & & \\
\hline & + & & & $=$ & \\
\hline
\end{tabular}




\section{Appendix G: Engagement Rubric}

Participant ID:

\section{Supplemental Course Activities Engagement}

\begin{tabular}{|l|l|}
\hline Workshop - Publisher Identification & Score \\
\hline 0: Did not identify correct publisher & \\
1: Identified correct publisher & \\
\hline
\end{tabular}

\begin{tabular}{|l|l|}
\hline Workshop - Source Evaluation & Score \\
\hline 0: Pre-Beginning (Does not understand what is being asked) & \\
1: Beginning (Describes source as accurate, reliable, or relevant with no elaboration) \\
2: Developing (Describes why a source is accurate, reliable, and/or relevant but analysis is \\
not fully mature or does not evaluate the source material) \\
3: Exemplary (Describes why a source is accurate, reliable, and/or relevant with an \\
evaluation of the source material)
\end{tabular}

\begin{tabular}{|l|l|}
\hline Workshop - Analysis of Citation Format (Chicago Manual of Style) & Score \\
\hline 0: No citations included & \\
1: Made an attempt at citing a source (e.g., link only, only parts of a citation) & \\
2: Has all the pieces required for a citation, but has stylistic errors. & \\
3: Perfectly formatted citation according to Chicago Manual of Style. & \\
\hline
\end{tabular}

Online Module Engagement - MAPS assignment

(Assignment - Complete all of the following: keyword activity, topic activity, and reflection)

1: Submitted one portion of assignment

2: Submitted two portions of assignment

3: Submitted all three portions of assignment

\section{Supplemental Course Activities - Engagement Score}

\begin{tabular}{|c|c|c|c|c|c|c|c|c|}
\hline $\begin{array}{c}\text { Workshop - Publisher } \\
\text { Identification (0-1) }\end{array}$ & $\begin{array}{c}\text { Workshop - Source } \\
\text { Evaluation (0-3) }\end{array}$ & $\begin{array}{c}\text { Workshop - Citation } \\
\text { Format (0-3) }\end{array}$ & $\begin{array}{c}\text { Online Module } \\
\text { Elements (1-3) }\end{array}$ & & \\
\hline & + & & + & & + & & $=$ \\
\hline
\end{tabular}

